\title{
2005 CAG Educational Needs Assessment report
}

\author{
Ronald Bridges MD FRCPC 1 , Sandra Daniels MSc ${ }^{2}$ \\ ${ }^{1}$ Chair, CAG Education Committee; ${ }^{2}$ CAG National Office
}

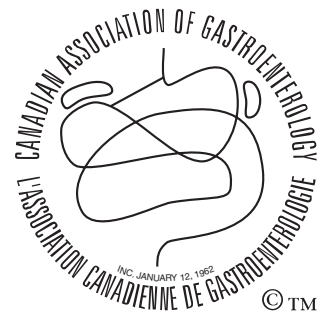

En français voir page 449

$\mathrm{T}$ he annual survey of Canadian Association of Gastroenterology (CAG) members' educational needs was conducted online during March and April, 2005. Two hundred fifty-five individuals completed the needs assessment. The topic most in demand for future educational events, similar to previous years, was inflammatory bowel disease (IBD) from the clinical perspective. Other highly rated topics included the basic science of IBD, endoscopy, upper gastrointestinal bleeding, pancreatitis/pancreatic disease and pharmacological therapeutics. Educational materials were by far judged to be the most valuable component of the exhibit area $(76 \%)$, and $42 \%$ reported repeated use of the online CAG Interactive Lecture Series.

The purpose of the CAG needs assessment was to provide guidance to the Executive and the CAG Education Committee on areas of greatest educational need. Conducting a needs assessment is a requirement for accreditation of educational events in accordance with the Royal College of Physicians and Surgeons of Canada Maintenance of Certification accreditation criteria.

\section{METHODS}

The Education Committee consists of Drs Janice Barkey, Jamie Gregor, John Fardy, Dana Farina, Marty Fishman, Terrence Moore, Alaa Rostom, Richard Schreiber and Connie Switzer. The needs assessment was the same as that used in 2004, apart from one question. Members were requested by e-mail to visit the CAG Web site to complete the simple 'tick box' survey. Data were compiled and analyzed at the CAG National Office.

The needs assessment included four sections. The first collected basic demographic information; the second questioned members on their interest in topics for educational events; the third section explored use of the online Interactive Lecture Series; and the fourth examined needs for the exhibit area at Canadian Digestive Diseases Week (CDDW).

Respondents were asked to rate their interest in 33 potential topics for educational events using a scale of 1 to 7 , where $1=$ no interest and 7 =extremely interested. Use of the Interactive Lecture Series was assessed by frequency category. For exhibits, respondents selected those items of greatest value to them.

\section{RESULTS}

Two hundred fifty-five individuals (approximately 29\%) of the solicited membership (with e-mail addresses) completed the needs assessment.

\section{Demographics}

Of the respondents, $76 \%$ were men and $24 \%$ were women. Regarding education, $73 \%$ were $\mathrm{MDs}$, $5 \%$ were $\mathrm{MD} / \mathrm{PhDs}, 15 \%$ were $\mathrm{PhD}$ and $6 \%$ held another degree. The majority of respondents $(82 \%)$ were predominantly hospital-rather than community-based.

Most replies were from Ontario members (37\%), followed by Alberta (19\%) and Quebec (18\%), with responses distributed roughly in proportion to provincial population.

Examining respondents' specialty or primary role, 56\% were gastroenterologists, 3\% identified hepatology as their focus, $4 \%$ were in pediatrics and $2 \%$ were surgeons. Basic and clinical scientists made up approximately $18 \%$ and $3 \%$, respectively, of respondents. Residents accounted for $8 \%$, and 'other' roles for $5 \%$.

Regarding where respondents spend their time, $67 \%$ identified clinical practice as their primary focus and $25 \%$ noted basic research. Administration accounted for 3\%, with 5\% reporting 'other' duties.

\section{Educational topics}

The mean interest scores for the 27 scientific educational topics, from the perspectives of basic science, clinical science and pediatrics, are shown in Figure 1. As in previous years, the highest mean interest score recorded (4.9) was for education in clinical IBD, followed closely by the basic science of IBD (score 4.6). IBD continues to be the highest scored topic within each of the categories of clinical, basic science and pediatrics. Clinical sessions on endoscopy (score 4.1), along with upper gastrointestinal bleeding, pancreatitis/pancreatic diseases and pharmacological therapeutics (all scored 3.8), and celiac disease (score 3.7) were also in demand. Mean scores for the remaining topics ranged from 2.2 to 4.9 for clinical topics, 1.7 to 4.6 for basic science topics and 1.2 to 2.0 for pediatrics.

Responses for nonscientific educational event topics are given in Figure 2. The highest score of 3.4 for 'GI and the internet' was still lower than the top-scored clinical topics.

\section{Interactive Lecture Series}

Forty-two per cent of respondents reported accessing the lectures series repeatedly, $11 \%$ had used it once, and $47 \%$ had never used the e-library (Figure 3).

\section{Exhibits}

Replies to the question 'Which of following would be most valuable to you in an exhibit area?' are shown in Figure 4. Respondents

The CAG is proud to acknowledge its Benefactor Corporate Sponsors:
Abbott Laboratories Ltd
AstraZeneca Canada Inc
Axcan Pharma Inc
Janssen-Ortho Inc
Pfizer Canada Inc
Schering Canada Inc 


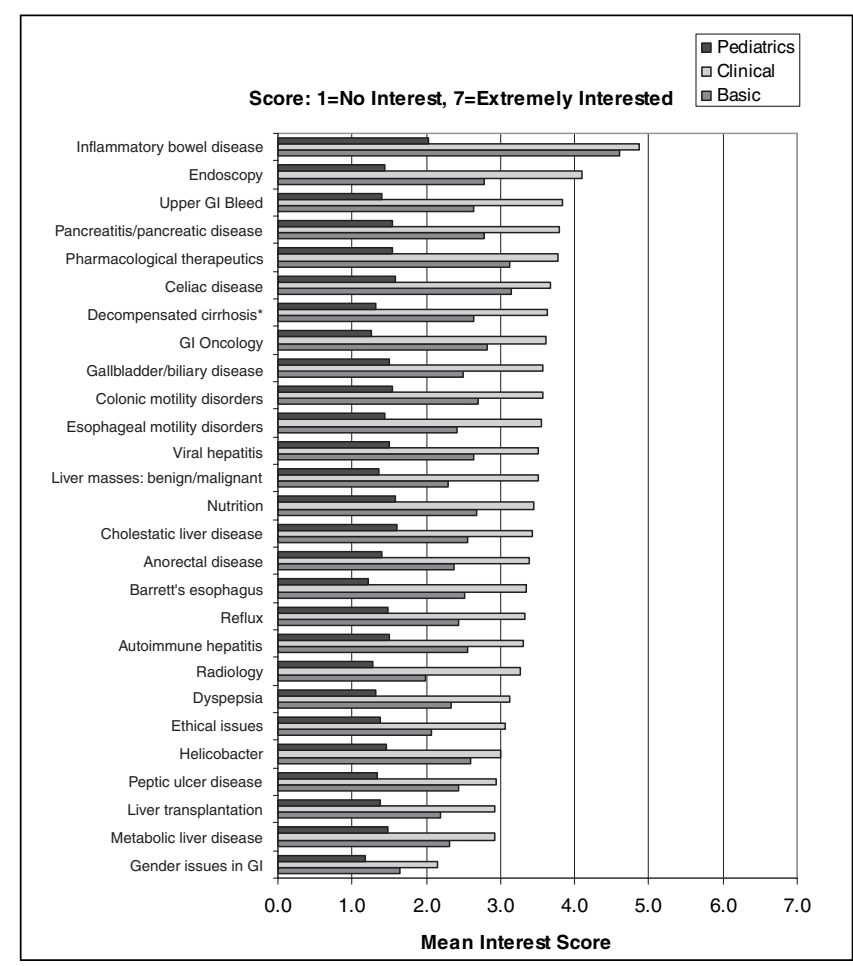

Figure 1) Mean interest score for potential educational topics (scientific). *Decompensated cirrhosis: ascites, varices, spontaneous bacterial peritonitis. GI Gastrointestinal

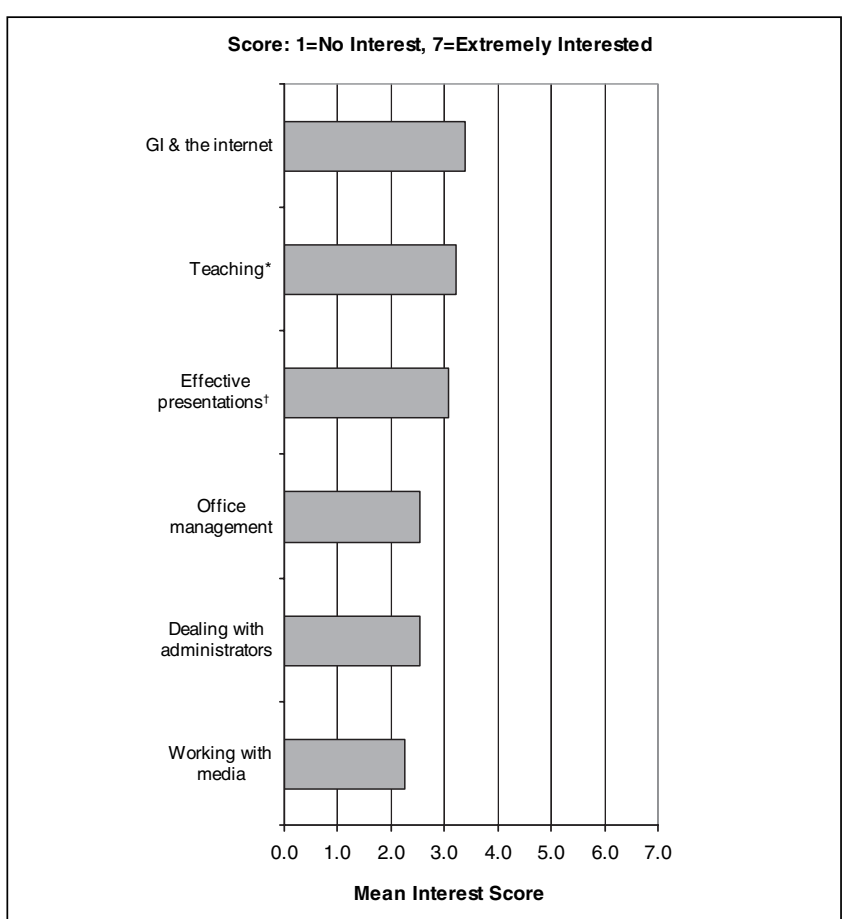

Figure 2) Mean interest score for potential educational topics (nonscientific). *Teaching theory and techniques; Developing effective presentations. GI Gastrointestinal

were allowed to select more than one item, thus, percentages do not sum to $100 \%$. The overwhelming favourite selected by $76 \%$ was Educational materials, with Interactive learning (53\%) and Abstracts (52\%) a distant second and third, respectively.

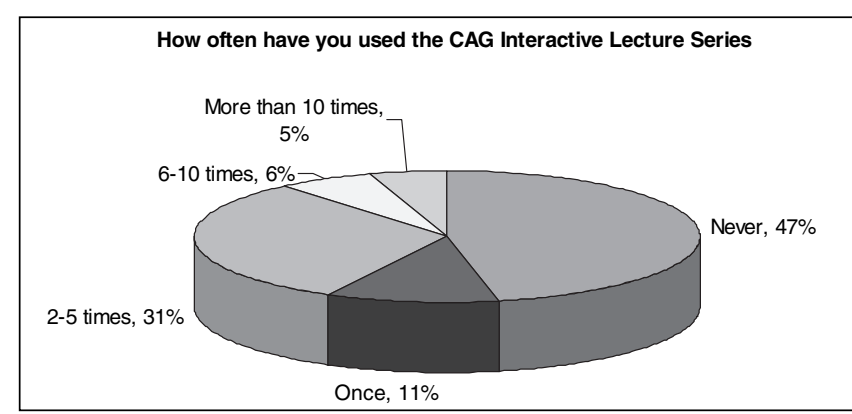

Figure 3) Use of the Canadian Association of Gastroenterology (CAG) Interactive Lecture Series library of presentations available online for use with CD-ROM

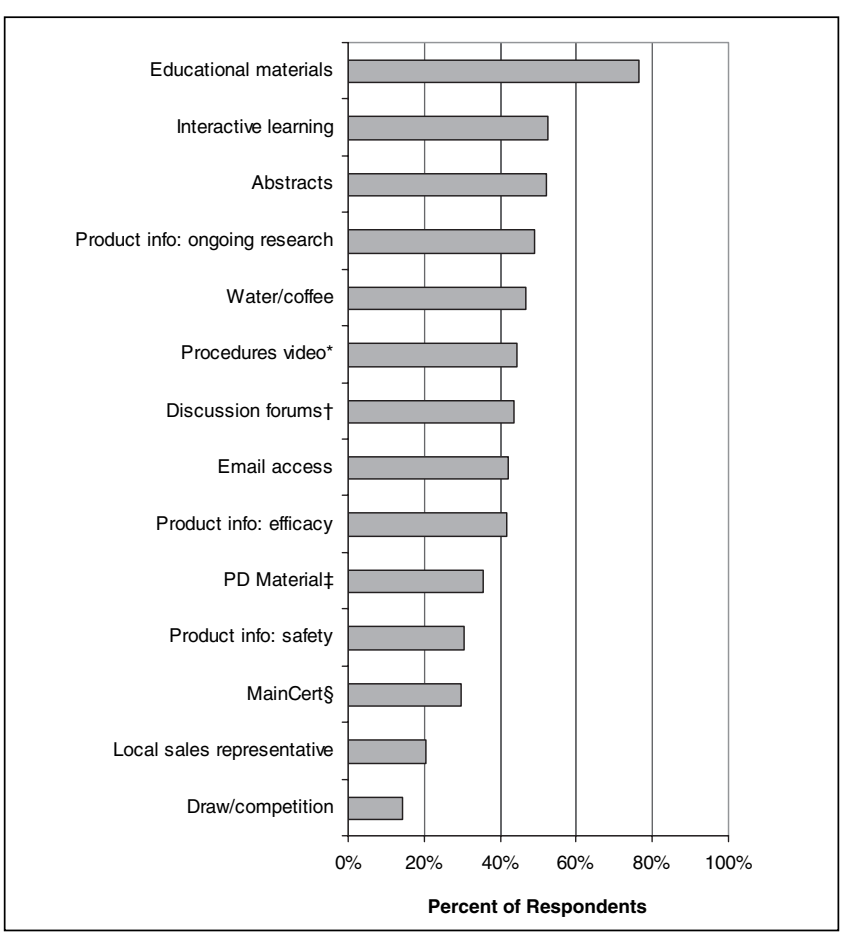

Figure 4) Needs for the exhibit area. *Video on endoscopyl colonoscopy or other procedures; ${ }^{\dagger}$ Discussion forums with key opinion leaders; Material for professional development (PD); §Accredited (Maintenance of Certification [MainCert]) personal learning objectives

\section{DISCUSSION}

This year's needs assessment saw one of the highest response rates on record. Approximately 29\% of the solicited membership participated, in comparison with 24\% (187) and 7\% (68) in 2003 and 2004 , respectively. Initial response to the survey was poor, but members are to be commended for enthusiastically answering a second request for input. Feedback was again largely from hospitalrather than community-based individuals, though less so than in 2003. The five most desired educational topics remain surprisingly consistent with previous years' surveys, despite holding sessions at both CDDW 2003 and CDDW 2004 in the areas of IBD, endoscopy and pancreatitis/pancreatic disease. The 2005 results have formed the basis of the 2006 CDDW program, and it is hoped that future assessments will draw more response from the community-based membership. 


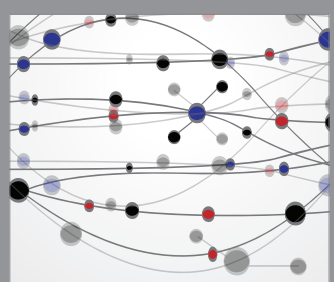

The Scientific World Journal
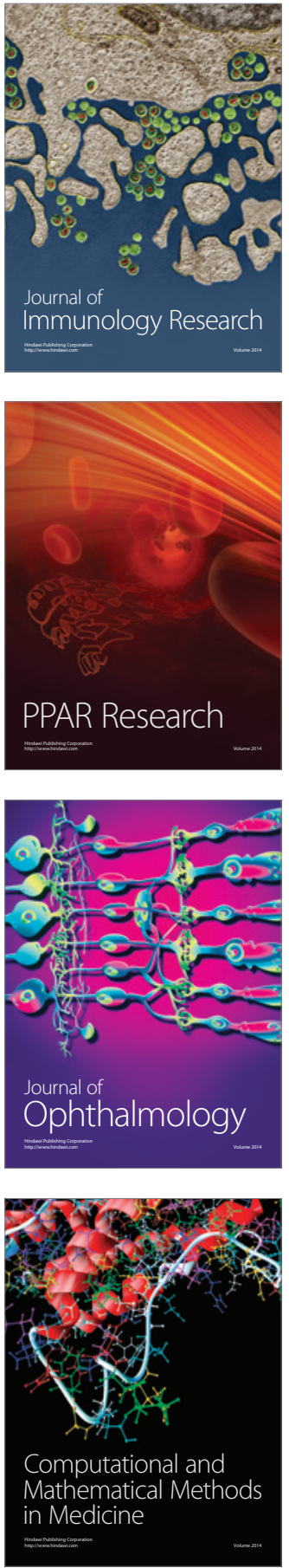

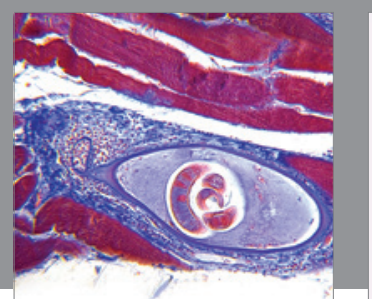

Gastroenterology Research and Practice

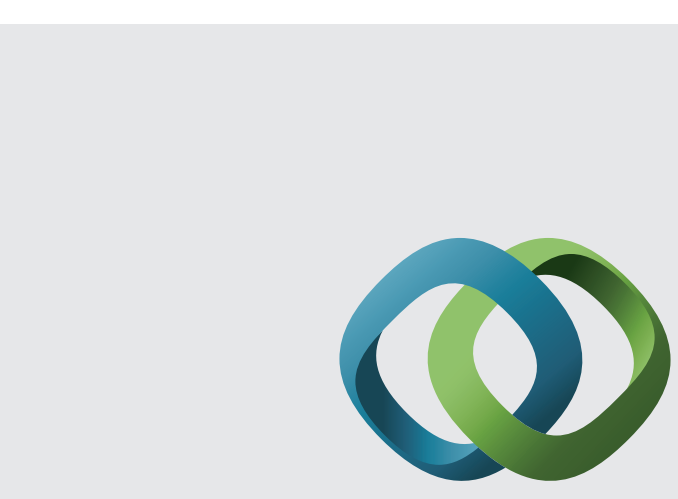

\section{Hindawi}

Submit your manuscripts at

http://www.hindawi.com
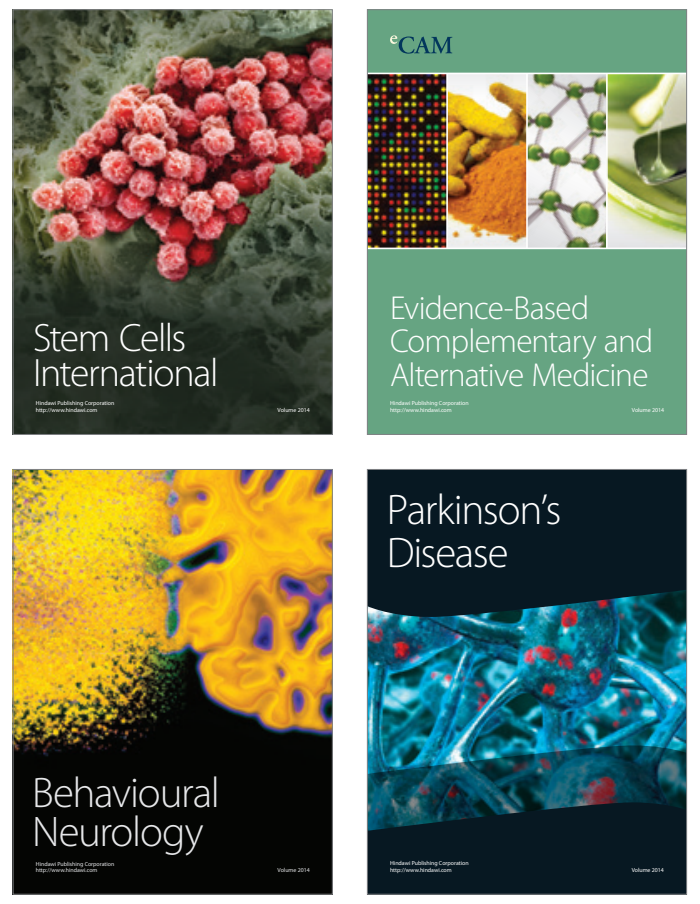
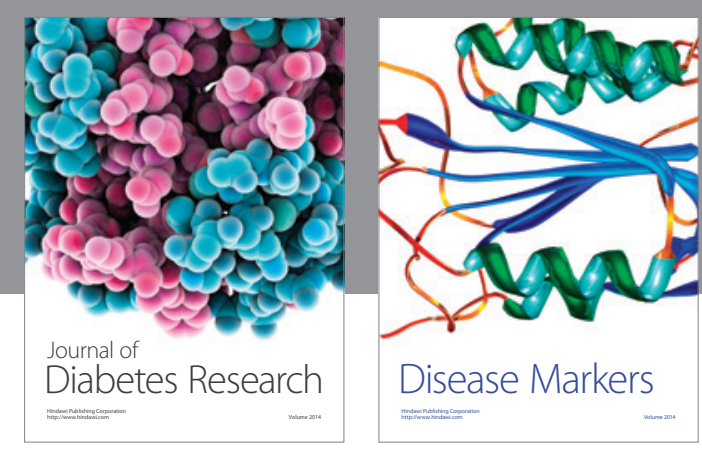

Disease Markers
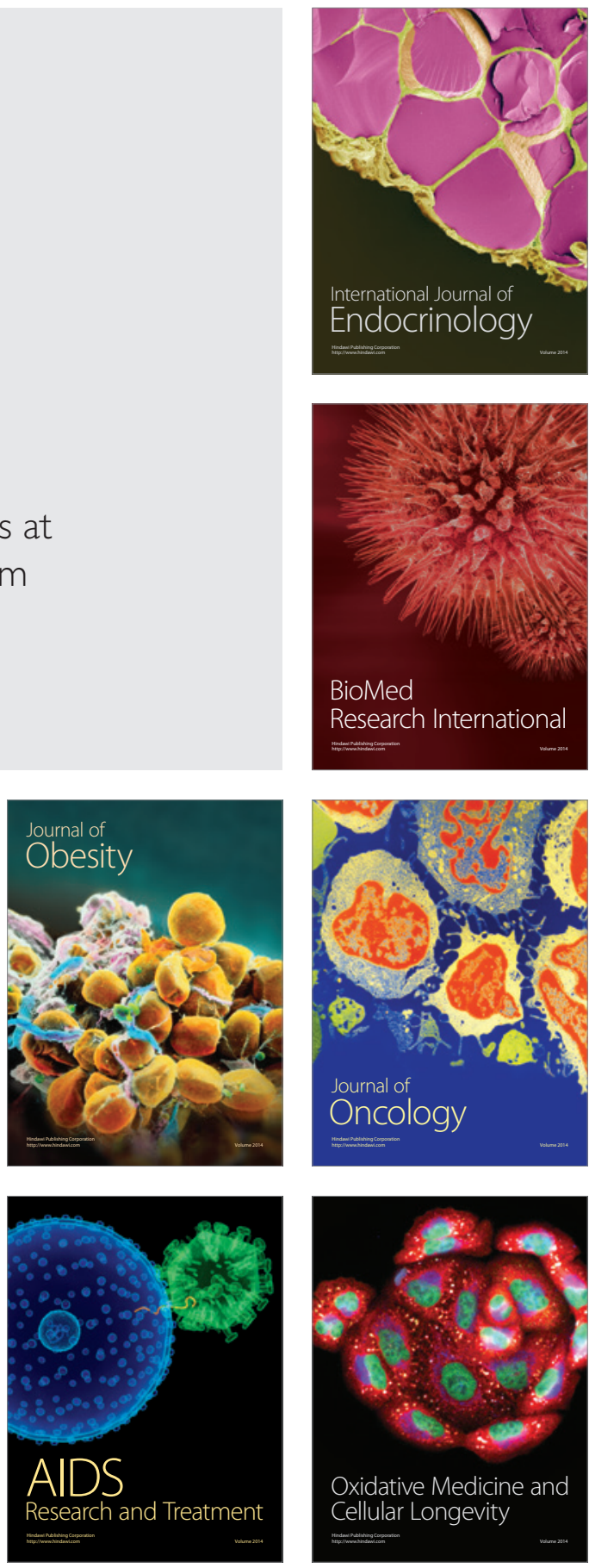